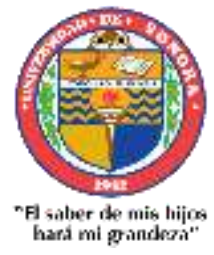

( Julio - Diciembre 2020)

Año 13.

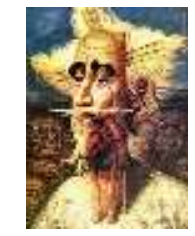

Revista de Investigación

Académica sin Frontera

Núm. 33

ISSN: 2007-8870

https://revistainvestigacionacademicasinfrontera.unison.mx/index.php/RDIASF

Recibido el 3 de junio de 2020. Dictaminado mediante arbitraje favorablemente 9 de octubre de 2020.

\title{
DISEÑO DE UNA RUTA GASTRONÓMICA DESDE LA PERSPECTIVA DEL TURISMO COMUNITARIO EN LA LOCALIDAD DEL PAREDÓN COLORADO
}

\author{
Sosa Covarrubias John \\ john.sosa@itson.edu.mx \\ Nieblas Borboa María Carolina \\ Baez Portillo María Marysol \\ Moncayo Rodríguez Lizette Marcela \\ Instituto Tecnológico de Sonora
}

\section{Resumen}

En el año 2018 la Organización Mundial del Turismo (OMT), menciona que durante décadas el turismo ha experimentado un continuo crecimiento y una profunda diversificación, hasta convertirse en uno de los sectores económicos que crecen con mayor rapidez en el mundo. Según Mamani, (2016), al paso de los años surgen las rutas turísticas, denominándose como tal a aquella vía que sobresale por estar rodeada de lugares que se consideran por algún motivo valiosos.

El objetivo del presente estudio es diseñar una ruta gastronómica en la localidad de Paredón Colorado, a través de la evaluación del potencial turístico, con la finalidad de crear una propuesta que permita incrementar el desarrollo económico en la localidad por medio del turismo gastronómico. Esta investigación tiene un enfoque cualitativo y está basada en la metodología de Boullón para el diagnóstico de los recursos turísticos y en la ficha del Ministerio de Comercio Exterior y Turismo de Perú para el diseño del producto turístico.

Como parte de los resultados de la fase diagnóstica se realizó un estudio Geosocioeconómico, un análisis de las tradiciones y cultura del lugar, la zonificación turística del sitio, la elaboración de la ficha de inventario de recursos naturales y culturales y por último se obtuvo el informe del potencial turístico de la localidad. Por otra parte, se diseñó la ruta gastronómica a partir de la generación de la idea, el análisis de la demanda y la competencia, el análisis económico, el diseño del itinerario y los canales de distribución de la misma.

Palabras clave: Ruta gastronómica, turismo comunitario, productos turísticos. 


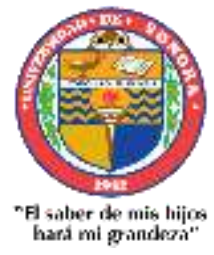

Año 13.

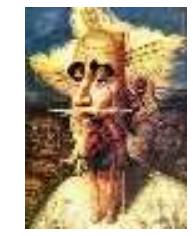

Revista de Investigación

Académica sin Frontera

Núm. 33

ISSN: 2007-8870

https://revistainvestigacionacademicasinfrontera.unison.mx/index.php/RDIASF

Recibido el 3 de junio de 2020. Dictaminado mediante arbitraje favorablemente 9 de octubre de 2020.

\section{DESIGN OF A GASTRONOMIC ROUTE FROM THE PERSPECTIVE OF COMMUNITY TOURISM OF PAREDON COLORADO}

In 2018, the World Tourism Organization (UNWTO) mentions that for decades tourism has experienced continuous growth and deep diversification, until it becomes one of the fastest growing economic sectors in the world. According to Mamani, (2016), over the years the tourist routes arise, being named as such to that road that stands out for being surrounded by places that are considered for some valuable reason.

The main pourpose of the present study is to design a gastronomic route in the locality of Paredón Colorado, through the evaluation of the tourism potential, with the purpose of creating a proposal that allows to increase the economic development in the locality through gastronomic tourism. This research has a qualitative approach and is based on Boullón's methodology for the diagnosis of tourism resources and on the file of the Ministry of Foreign Trade and Tourism of Peru for the design of the tourism product.

As part of the results of the diagnostic phase, a Geo-socioeconomic study was carried out, an analysis of the traditions and culture of the place, the tourist zoning of the site, the preparation of the inventory sheet of natural and cultural resources and finally it was obtained the report of the tourist potential of the town. On the other hand, the gastronomic route was designed based on the generation of the idea, the analysis of demand and competition, the economic analysis, the design of the itinerary and its distribution channels.

Keywords: Gastronomic route, community tourism, tourist products.

\section{Introducción}

El turismo se ha convertido en uno de los principales actores del comercio internacional $\mathrm{y}$, representa al mismo tiempo una de las principales fuentes de ingresos de numerosos países en desarrollo (OMT, 2018). 


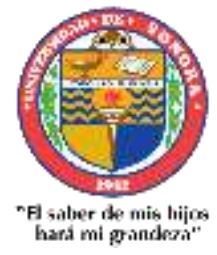

( Julio - Diciembre 2020)

Año 13.

Núm. 33

ISSN: 2007-8870

https://revistainvestigacionacademicasinfrontera.unison.mx/index.php/RDIASF

Recibido el 3 de junio de 2020. Dictaminado mediante arbitraje favorablemente 9 de octubre de 2020.

En base a los cambios de las necesidades que presentan hoy en día los turistas, el turismo gastronómico ha sido uno de los que ha causado interés en las personas, las cuales deciden el destino basándose en el placer que obtendrán al degustar los platillos típicos del lugar.

En México este tipo de turismo ha ido tomando relevancia desde que en 2010 su cocina fue declarada Patrimonio Intangible de la Humanidad por la Unesco. E diseñar una ruta gastronómica puede beneficiar a los habitantes de la Localidad de Paredón Colorado si el diseño de la ruta se lleva a cabo de manera adecuada.

Con base a lo anteriormente mencionado, surge la necesidad de dar respuesta a la siguiente interrogante: ¿El diseño de una ruta gastronómica, tendrá beneficios para la Localidad de Paredón Colorado?

Es por ello que el objetivo es diseñar una ruta gastronómica en la localidad de Paredón Colorado, a través de una investigación y evaluación del potencial turístico, con la finalidad de tener una propuesta que al ejecutarla incremente el desarrollo económico en la localidad por medio del turismo gastronómico.

La presente investigación se enfocará en obtener algunos beneficios para la localidad del Paredón Colorado, el cual será el diseño de una ruta gastronómica, puede ayudar al desarrollo económico si una empresa local o privada se interesa en la implementación de la ruta, dejando una derrama económica en la localidad y a habitantes involucrados en dicha ruta, también traerá como beneficio mayor afluencia de visitantes. El realizar esta investigación beneficiará a la autora porque 


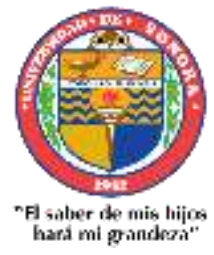

Año 13.

Núm. 33

ISSN: 2007-8870

https://revistainvestigacionacademicasinfrontera.unison.mx/index.php/RDIASF

Recibido el 3 de junio de 2020. Dictaminado mediante arbitraje favorablemente 9 de octubre de 2020.

al diseñar una ruta gastronómica en la localidad del Paredón Colorado, puede ayudar a buscar un plan de implementación y de esta forma llevarla a cabo y obtener una derrama económica. Por otra parte, la presente ayudará a futuros investigadores a profundizar el tema y buscar otras alternativas que puedan aportar un beneficio a la localidad.

\section{Desarrollo del tema}

El turismo es el conjunto de relaciones y fenómenos producidos por el desplazamiento y la permanencia de personas fuera de su lugar de domicilio, en tanto dicha permanencia y desplazamiento no estén motivados por una actividad lucrativa (Ramírez,1981).

En el año 2001 la Organización Mundial De Turismo (OMT) menciona que el turismo comprende las actividades que realizan las personas durante sus viajes y estancias en lugares distintos al de su entorno habitual, por un período de tiempo consecutivo inferior a un año, con fines de ocio, y otros motivos no relacionados con el ejercicio de una actividad remunerada en el lugar visitado.

Ramírez, (1981) y la OMT, (2001) coinciden en que, el turismo es el desplazamiento de personas fuera de su lugar de origen. La realización de la actividad es con fines de ocio con el objetivo de crear nuevas experiencias y los viajes no son motivados por actividades lucrativas. 


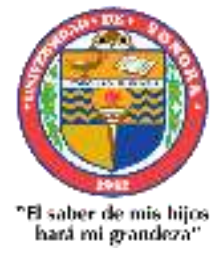

( Julio - Diciembre 2020)

Año 13.

Núm. 33

ISSN: 2007-8870

https://revistainvestigacionacademicasinfrontera.unison.mx/index.php/RDIASF

Recibido el 3 de junio de 2020. Dictaminado mediante arbitraje favorablemente 9 de octubre de 2020.

Desde el punto de vista conceptual, el producto turístico no es más que un conjunto de prestaciones, materiales e inmateriales, que se ofrecen con el propósito de satisfaces los deseos o las expectativas del turista. Es en realidad, un producto compuesto que puede ser analizado en función de los componentes básicos que lo integran: atractivos, facilidades y acceso (Acerenza, 1993).

En el año 2004 la Secretaría de Turismo del gobierno federal de México define el producto turístico como el conjunto de componentes tangibles e intangibles que incluye: recursos y atractivos, equipamientos e infraestructura, servicios, actividades recreativas, imágenes y valores simbólicos, que ofrecen unos beneficios capaces de atraer a grupos determinados de consumidores, porque satisfacen las motivaciones y expectativas relacionadas con su tiempo libre.

Otro aspecto a considerar es la ruta turística, la cual es la creación de un clúster de actividades y atracciones que incentivan la cooperación entre diferentes áreas y que sirven de vehículo para estimular el desarrollo económico de determinadas zonas geográficas a través del turismo, implicando, por tanto, que las rutas turísticas deben tener una serie de elementos que la respalden como destino turístico (Briedenhann y Wickens, 2003).

Montecinos, (2012) define ruta gastronómica como un itinerario con un origen, dimensión territorial, y configuración estructural especifica que enlaza destinos, productos, atracciones servicios y actividades fundamentales en la producción, creación, transformación, evolución, preservación, salvaguarda, 


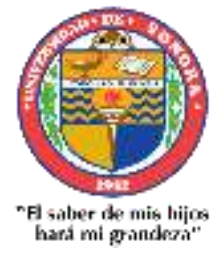

Año 13.

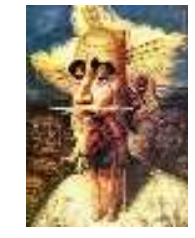

Revista de Investigación

Académica sin Frontera

Núm. 33

ISSN: 2007-8870

https://revistainvestigacionacademicasinfrontera.unison.mx/index.php/RDIASF

Recibido el 3 de junio de 2020. Dictaminado mediante arbitraje favorablemente 9 de octubre de 2020.

consumo, uso, gozo, disfrute de manera saludable y sostenible del patrimonio gastronómico mundial cultural, natural, inmaterial, mixto y todo lo que respecta al sistema alimenticio de la humanidad.

Según Hall y Mitchell, (2001) el turismo gastronómico es la visita a productores (tanto primarios como secundarios) de alimentos, festivales gastronómicos, restaurantes y lugares específicos, donde la degustación de alimentos y toda la experiencia inherente son el motivo principal para viajar.

En el año 2009, Henderson señala que el turismo gastronómico ocurre en los lugares donde los turistas pueden consumir gastronomía, como los restaurantes; y que la experiencia del turismo gastronómico puede ocurrir aún en el contexto de las tiendas convencionales, los festivales gastronómicos, las escuelas de hotelería y las quintas que buscan atraer visitantes con su gastronomía.

Por otro lado, Oliveira, (2008) procura presentar una definición abarcadora, señalando que el turismo gastronómico es el desplazamiento de visitantes, tanto de turistas como de excursionistas, cuyo motivo principal es la gastronomía, y que involucra prácticas que van desde el mero desplazamiento del lugar de residencia hacia un restaurante donde degustar un plato; el desplazamiento hacia un determinado destino para aprender a preparar determinados alimentos: y hasta la realización de rutas gastronómicas con la intención de aprender algo más sobre cierta gastronomía. 


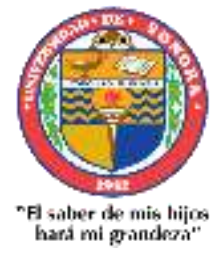

( Julio - Diciembre 2020)

Año 13.

Núm. 33

ISSN: 2007-8870

https://revistainvestigacionacademicasinfrontera.unison.mx/index.php/RDIASF

Recibido el 3 de junio de 2020. Dictaminado mediante arbitraje favorablemente 9 de octubre de 2020.

Según la Secretaría de Turismo del Gobierno Federal de México, (2002) el potencial turístico de una región o municipio se debe evaluar en forma integral, considerando los factores determinantes tanto de la oferta de servicios turísticos prevalecientes localmente, como de los que definen la demanda actual y esperada de los posibles visitantes de la región.

El potencial turístico de una región depende de la valoración que se realiza sobre sus recursos, así como del nivel de estructuración de sus atractivos en productos turísticos. La valoración de los recursos incluye, como etapa previa, la elaboración de un inventario que integre la información descriptiva más relevante de dichos recursos (Maass, 2009).

De acuerdo con la Secretaría de Turismo del gobierno federal de México, (2002) y Maass, (2009) la evaluación del potencial turístico se realiza con la finalidad de, obtener los recursos con los que cuenta el destino y una vez identificados y analizados, se decide qué tipo de productos turísticos se pueden llevar a cabo, y así mismo, a qué tipo de mercado va dirigido. El turismo solo tiene lugar si existen ciertas atracciones que motivan al viajero de abandonar su domicilio habitual y permanecer cierto tiempo fuera de él. Respecto a la actividad turística, guardan la misma relación que los llamados recursos naturales hacia otras actividades productivas: nada valen sobre el mercado si no son puestos en valor y explotados y como los naturales, hay casos en que los atractivos turísticos son perecederos y no renovables. 


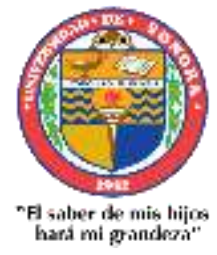

Año 13.

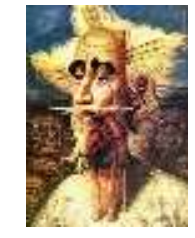

Revista de Investigación

Académica sin Frontera

Núm. 33

ISSN: 2007-8870

https://revistainvestigacionacademicasinfrontera.unison.mx/index.php/RDIASF

Recibido el 3 de junio de 2020. Dictaminado mediante arbitraje favorablemente 9 de octubre de 2020.

Al hablar de destino se hace referencia a un lugar de llegada, de acogida, de recepción definitiva de los visitantes, lugar hacia donde tiene que desplazarse la demanda para consumir el producto turístico (Sancho, 1998).

Para Bull, (1994) es el país o ciudad hacia el que se dirigen los visitantes, teniéndolo como su principal objetivo. Otros autores como Cooper, (1993), definen el destino turístico como la concentración de instalaciones y servicios diseñados para satisfacer las necesidades de los turistas.

Tal es el caro de un servicio turístico, el cual se define como un conjunto de actividades perfectamente diferenciadas entre sí, pero íntimamente relacionadas, que funcionan en forma armónica y coordinada con el objeto de responder a las exigencias de servicios planteados por la composición socio-económica de una determinada corriente turística (Ramírez, 2002).

Según la OEA, (1980) los servicios turísticos, se describen como el resultado de las funciones, acciones y actividades ejecutadas coordinadamente, por el sujeto receptor, permiten satisfacer al turista, hacer uso óptimo de las facilidades o industria turística y darle valor económico a los atractivos o recursos turísticos.

Como pudiera ser el turismo gastronómico, el cual tiene por objetivo conocer y degustar la gastronomía típica del lugar e incluye productos turísticos relacionados como rutas gastronómicas, visitas a mercados y a productores gastronómicos, 


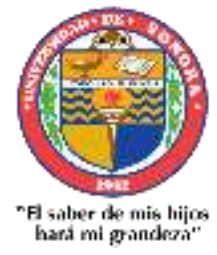

( Julio - Diciembre 2020)

Año 13.

Núm. 33

ISSN: 2007-8870

https://revistainvestigacionacademicasinfrontera.unison.mx/index.php/RDIASF

Recibido el 3 de junio de 2020. Dictaminado mediante arbitraje favorablemente 9 de octubre de 2020.

fiestas y jornadas gastronómicas, eventos gastronómicos, museos, clases y talleres de cocina local (OMT, 2013).

Según barrera, (1999), una ruta gastronómica es un itinerario que permite reconocer y disfrutar de forma organizada el proceso productivo agropecuario, industrial y degustación de la cocina regional, a su vez las rutas gastronómicas se organizan en torno a un producto clave que caracteriza la ruta y le otorga su nombre.

La ruta debe ofrecer a quienes la recorren una serie de placeres y actividades relacionadas con los elementos distintivos de la misma: comida, producción, agroindustrial, actividades rurales, entretenimientos en la naturaleza y actividades propias de la cultura regional.

Dentro de las manifestaciones culturales se encuentra la gastronomía típica como muestra de la idiosincrasia del pueblo y cuyo potencial como atractivo turístico ha sido demostrado por países que la han incorporado dentro de su oferta, creando rutas turísticas que le permiten al visitante conocer y degustar los platos, dulces y bebidas típicas (González, 2013).

Un claro ejemplo de estos acontecimientos es el turismo gastronómico en el estado de Guanajuato, el cual ha dejado una derrama económica en el estado, de acuerdo con datos del primer anexo estadístico del IV informe de gobierno de Miguel Márquez, en 2015 la Secretaría de turismo estatal entregó apoyos económicos por 9 millones 743 mil 807 pesos para la realización de eventos gastronómicos. Dichos 


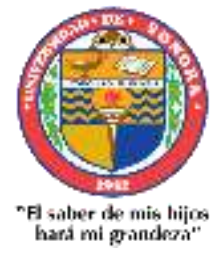

( Julio - Diciembre 2020)

Año 13.

Núm. 33

ISSN: 2007-8870

https://revistainvestigacionacademicasinfrontera.unison.mx/index.php/RDIASF

Recibido el 3 de junio de 2020. Dictaminado mediante arbitraje favorablemente 9 de octubre de 2020.

eventos tuvieron una concurrencia de más de 222 mil visitantes, señalan los datos del informe de Márquez (2015).

En el año 2016 la revista WTM Bussines realizó una investigación que arrojó a nivel país, el Estado de Guanajuato, como un caso de éxito en turismo gastronómico, posicionándolo como el sexto destino más visitado en México por su oferta turística y grandes eventos culturales, incluyendo la Cumbre Internacional de la gastronomía, en la que, en el año 2016, en su quinta edición, se realizaron más de 33 eventos y 120 actividades de gastronomía en 11 municipios del Estado. Participaron, además, 18 chefs internacionales, 13 chefs nacionales, 28 chefs

estatales y más de 40 cocineras tradicionales de Guanajuato, Querétaro, Zacatecas, San Luis Potosí y CDMX.

\section{Metodología}

La presente investigación tiene un enfoque cualitativo, según Sampieri, (2014) utiliza la recolección de datos y análisis de los datos para afinar las preguntas de la investigación o revelar nuevas interrogantes en el proceso de interpretación.

Patton, (2011) define los datos cualitativos como descripciones detalladas de situaciones, eventos, personas, interacciones, conductas observadas y sus manifestaciones, en cambio Sampieri, (2014) define los datos cualitativos como, evidencia o información simbólica verbal, audiovisual o en forma de texto e imágenes. 


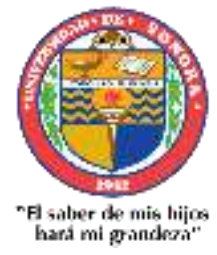

Año 13.

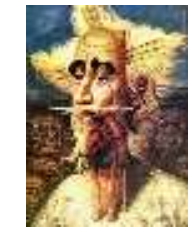

Revista de Investigación

Académica sin Frontera

Núm. 33

ISSN: 2007-8870

https://revistainvestigacionacademicasinfrontera.unison.mx/index.php/RDIASF

Recibido el 3 de junio de 2020. Dictaminado mediante arbitraje favorablemente 9 de octubre de 2020.

Participantes: En esta investigación se utilizó una ficha de inventario turístico, la cual se aplicó en la localidad de Paredón Colorado, para que el llenado de la ficha se llevará a cabo fue necesaria la ayuda de habitantes con un rango de edad entre los 35 y 70 años, de quienes se obtuvo información a través de entrevistas.

Materiales: En la presente investigación se utilizó como instrumento la ficha de recopilación de datos para información del inventario de recursos turísticos del Ministerio de Comercio Exterior y Turismo de Perú, (2012), la cual consta de cinco etapas, clasificándose los recursos turísticos como categorías, tipos y subtipos. Dentro de las categorías se pueden encontrar sitios naturales, manifestaciones culturales, y folklore.

La primera etapa tiene como objetivo obtener información del recurso, es decir, su nombre, ubicación geográfica, categoría, tipo y subtipo, descripción y particularidades con las que cuenta. Se debe evaluar cómo se encuentra actualmente el lugar y el tipo de visitante que recibe, posteriormente, se evalúa el tipo de ingreso, la época y horario en la que se visita el lugar, y si se cuenta con la infraestructura básica, actividades y servicios.

Después, en la segunda etapa, se recopila información secundaria, se obtiene de datos emitidos por los gobiernos central, local y/o regional, también de bibliografía existente, revistas u organismos especializados. 


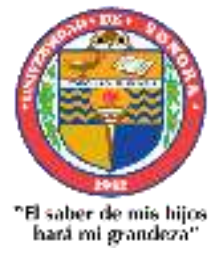

Año 13.

Núm. 33

ISSN: 2007-8870

https://revistainvestigacionacademicasinfrontera.unison.mx/index.php/RDIASF

Recibido el 3 de junio de 2020. Dictaminado mediante arbitraje favorablemente 9 de octubre de 2020.

En la tercera etapa, se registra la información, es decir se realiza el llenado de la ficha por medio de entrevistas, donde se plasma la información obtenida por parte de las personas de la localidad.

En la cuarta etapa, se lleva a cabo, el procesamiento de la información recopilada y por último en la quinta etapa, se realizó la elaboración del informe, documento donde se plasma el resumen y principales recursos turísticos con los que cuenta.

Procedimiento: la metodología es integrada por cinco fases.

Fase I: conceptos guía para el fomento del turismo cultural y la conservación del patrimonio:

En la primera fase se encontrará información general sobre el turismo cultural, así como las prácticas de sostenibilidad que se están utilizando actualmente para la conservación de la cultura.

Fase II: primeros pasos para la elaboración de productos de turismo cultural: En la segunda fase se muestra una descripción de las características que definen si es un producto de turismo cultural, así como una serie de preguntas que ayudan a verificar si la idea que se tiene cumple con las características antes mencionadas, también se define en qué estado de avance se encuentra y los requerimientos que se tienen en el momento. 


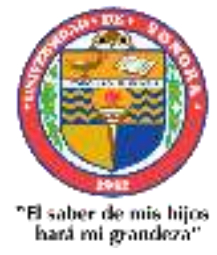

Año 13.

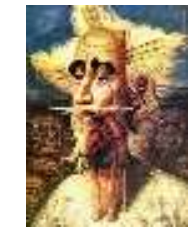

Revista de Investigación

Académica sin Frontera

Núm. 33

ISSN: 2007-8870

https://revistainvestigacionacademicasinfrontera.unison.mx/index.php/RDIASF

Recibido el 3 de junio de 2020. Dictaminado mediante arbitraje favorablemente 9 de octubre de 2020.

Fase III: diseño de productos de turismo cultural:

Posteriormente en la tercera fase, una vez identificado el estado que se encuentra su idea es necesario recibir una orientación para definir, planificar e iniciar con la comercialización del producto, en esta fase se explica detalladamente como se debe de diseñar el producto y el procedimiento que se debe seguir.

Fase IV: Diseño de plan de negocios turísticos culturales:

Después en la cuarta etapa en esta etapa se explica cómo se puede mejorar y diversificar un producto cultural en caso de que ya se cuente con uno, se explica el procedimiento de un plan de negocio con la finalidad de fortalecer el emprendimiento que se tiene con el producto de turismo cultural.

Fase V: Recomendaciones:

Por último, en la quinta fase se adjuntan recomendaciones operativas que se centran en ayudar a potenciar la vivencia cultural del visitante con el fin de que el producto que se ofrece tenga un impacto positivo en la experiencia del visitante.

La presente investigación se enfoca en las primeras 3 fases de la guía metodológica, esto debido a que no se cuenta con un producto en el mercado, por lo tanto, no se podría elaborar un plan de negocios ya que apenas se tiene la idea del producto y se tiene como propósito el diseño de una ruta gastronómica. 


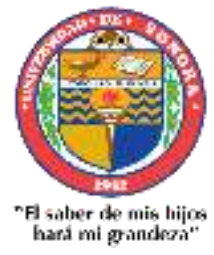

Año 13.

Núm. 33

ISSN: 2007-8870

https://revistainvestigacionacademicasinfrontera.unison.mx/index.php/RDIASF

Recibido el 3 de junio de 2020. Dictaminado mediante arbitraje favorablemente 9 de octubre de 2020.

Finalmente, en la cuarta etapa se determinarán las conclusiones y recomendaciones a las que se llegarán con la presente investigación, es decir de qué manera se pueden aprovechar los recursos turísticos para beneficio de la localidad.

\section{Resultado y discusión}

\section{Diagnóstico turístico de Paredón colorado}

El presente diagnóstico se basa en la metodología de Buollón, (1997), la cual consta de cinco fases, la primera trata de un estudio Geo-socioeconómico, la segunda es sobre el análisis de las tradiciones y cultura del lugar, posteriormente la tercera es la zonificación turística, después en la cuarta etapa la ficha de inventario de recursos naturales y culturales y por último el informe del potencial turístico de la localidad.

\section{Fase I estudio Geo-socioeconómico.}

La localidad de Paredón colorado (paredón viejo) esta situado en el Municipio de Benito Júarez en el Estado de Sonora, la población es de 1393 hombres y 1272 mujeres (Pueblos de México en Internet, 2017).

Cuenta con un total de 2 mil 665 habitantes, la mayoría se dedica a la pesca y comercialización del producto, en el pueblo hay al menos seis restaurantes que ofrecen una gran variedad de mariscos frescos y cocinados (Rodríguez, s.f.). 


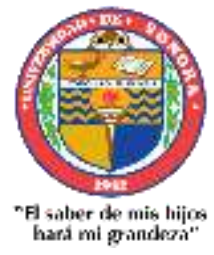

Año 13.

Núm. 33

ISSN: 2007-8870

https://revistainvestigacionacademicasinfrontera.unison.mx/index.php/RDIASF

Recibido el 3 de junio de 2020. Dictaminado mediante arbitraje favorablemente 9 de octubre de 2020.

En paredón colorado hay 702 viviendas, de ellas el $85.83 \%$ cuentan con los servicios de electricidad, $87.92 \%$ tiene agua entubada, el $87,60 \%$ tiene excusado o sanitario, el 54,91\% radio, el 88,57\% televisión, el 64,73\% refrigerador, el 35,27\% lavadora, el 19,48\% automóvil, el 5,31\% una computadora personal, el 26,73\% teléfono fijo, el $49,92 \%$ teléfono celular, y el 2,42\% Internet (Pueblos de México en Internet , 2017).

En cuanto a educación, la localidad cuenta con preescolar, primaria con turno matutino y vespertino, escuela secundaria técnica y una preparatoria, es de acceso para habitantes de la localidad, y comunidades aledañas, como aceitunitas y paredoncito.

\section{Fase II Análisis de las tradiciones y culturas}

En Paredón colorado a lo largo del año se manifiesta la cultura mayo a través de la tradición local, algunas de ellas son:

Fiestas tradicionales

- Día de la virgen de Guadalupe (diciembre)

- Día de la virgen del Carmen (julio)

- Día de la marina (junio)

- Velación de cristo (Semana Santa)

\section{Gastronomía}

- Guacabaqui

- Gallina pinta

- Cocido 
Revista de Investigación

Año 13.

Académica sin Frontera

Núm. 33

ISSN: 2007-8870

https://revistainvestigacionacademicasinfrontera.unison.mx/index.php/RDIASF

Recibido el 3 de junio de 2020. Dictaminado mediante arbitraje favorablemente 9 de octubre de 2020.

- Lisas fritas

- Ceviche de pescado

- Caldo largo

- Lisas ahumadas

- Cahuamanta

- Machaca de camarón

- Coctel de camarón

- Tostadas de jaiba

Monumentos histórico-culturales:

- Iglesia de nuestra señora de Guadalupe

- Iglesia sector yoreme

- Ramada de pascolas

\section{Fase III Zonificación turística}

A través de Google maps se diseñaron algunos mapas que muestran la ubicación geográfica de los principales municipios que visitan la localidad del paredón colorado. A continuación, se muestran los mapas diseñados.

En la figura 1 se puede observar la ubicación geográfica de la localidad del paredón colorado a la ciudad de Obregón. 
"Fl silser ite mis hijos

Año 13.

Núm. 33

ISSN: 2007-8870

$\underline{\text { https://revistainvestigacionacademicasinfrontera.unison.mx/index.php/RDIASF }}$

Recibido el 3 de junio de 2020. Dictaminado mediante arbitraje favorablemente 9 de octubre de 2020.

Figura 1. Ubicación geográfica

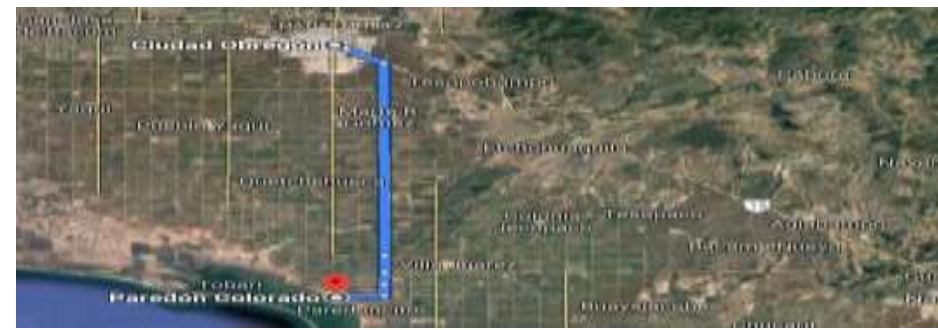

Fuente: Google maps (2019).

En la figura 2 a través de Google Maps se muestra la ubicación geográfica de la localidad del paredón colorado al municipio de Navojoa.

Figura 2. Ubicación geográfica

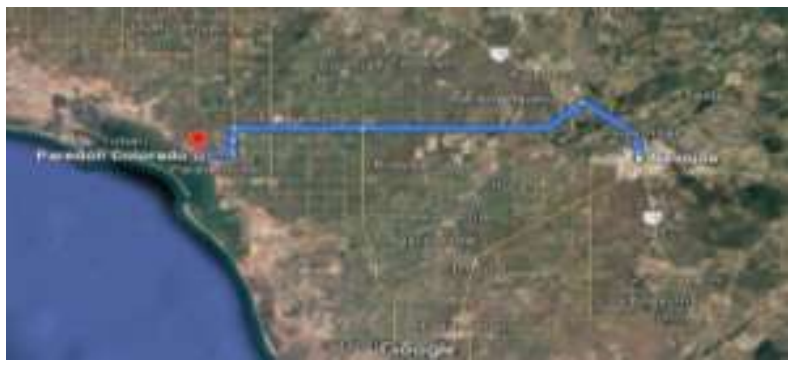

Fuente: Google maps (2019).

En la figura 3 se puede apreciar la ubicación geográfica y la distancia existente entre la localidad de paredón colorado y la isla Huivulai.

Figura 3. Ubicación geográfica de la isla Huivulai

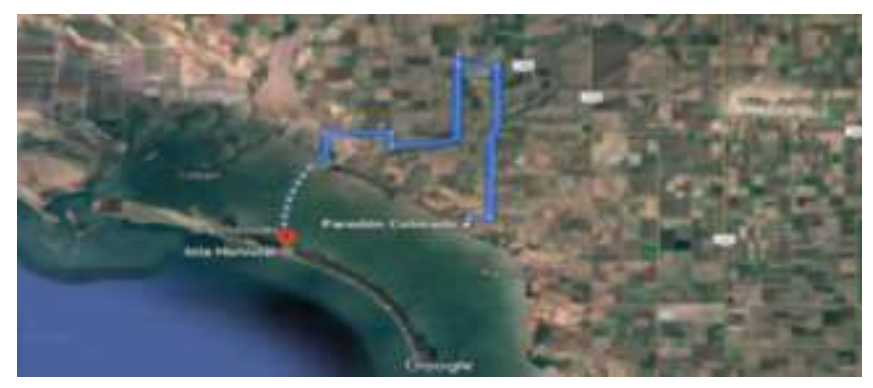

Fuente: Google maps (2019). 


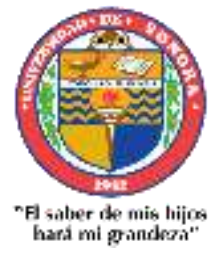

Año 13.

Núm. 33

ISSN: 2007-8870

https://revistainvestigacionacademicasinfrontera.unison.mx/index.php/RDIASF

Recibido el 3 de junio de 2020. Dictaminado mediante arbitraje favorablemente 9 de octubre de 2020.

\section{Fase IV Ficha de inventario de recursos naturales y culturales.}

En la cuarta fase se llevó a cabo el instrumento utilizado en la investigación denominado ficha de inventario de recursos naturales y culturales, donde se obtuvo recopilación de información y se dieron a conocer aspectos importantes de Paredón que ayudaron a identificar las oportunidades que se tienen dentro de localidad antes mencionada.

Para el llenado de la ficha fue necesario acudir a la localidad realizando visitas de campo con el fin de entrevistar a los habitantes y obtener información veraz, también se hicieron investigaciones por medio de páginas para obtener datos que los habitantes no sabían con exactitud, todo con la finalidad de conseguir una evaluación completa y tomar decisiones a partir de ahí.

\section{Fase V Informe del potencial turístico}

A partir de la recolección de datos obtenidos al realizar la ficha de recursos naturales y culturales de la localidad del Paredón colorado, se llegó a la conclusión que en la localidad se hacen presente manifestaciones culturales, que a lo largo del año los habitantes mantienen vivas las tradiciones del lugar a través de fiestas.

Desde la perspectiva natural, dentro de la localidad del paredón colorado se encuentra ubicada la isla Huivulai de diesciete kilómetros de largo y 1.2 de ancho, en su hábitat, se encuentra un pozo de agua dulce en el que proliferan palmas 


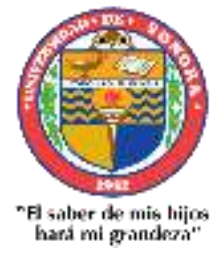

( Julio - Diciembre 2020)

Año 13.

Núm. 33

ISSN: 2007-8870

https://revistainvestigacionacademicasinfrontera.unison.mx/index.php/RDIASF

Recibido el 3 de junio de 2020. Dictaminado mediante arbitraje favorablemente 9 de octubre de 2020.

datileras, y es albergue para diversas aves como la garza, corveta, grulla, albatros, sirirí colorado, pelícano y gaviota.

Por último, en la localidad del Paredón los principales alimentos consumidos por sus habitantes son los mariscos, que es un recurso que se puede utilizar turísticamente, ya que investigaciones revelan que el principal atractivo del lugar es su gastronomía, donde cada fin de semana visitantes regionales degustan platillos en los diferentes restaurantes que se encuentran en el lugar.

Con la información obtenida, se considera que es viable crear rutas que incluyan paseos por la isla Huivulai, donde se puedan hacer diferentes actividades como pescar, caminata por las dunas de arena, y camping, así como degustar los platillos típicos del lugar elaborados en base a mariscos pescados por los habitantes del lugar, también se pueden llevar a cabo talleres donde los visitantes aprendan hacer artesanías con materiales de la isla como son conchas de mar, caballitos de mar y caracoles.

\section{Diseño de la ruta.}

La creación de la ruta consta de cuatro etapas las cuales son, generación de la idea, diseño de la ruta, análisis económico y por último la distribución de la ruta que se utilizará para atraer flujo de turistas a la localidad y realicen la ruta.

A través de una aplicación se crearon flyer, con el objetivo de dar a conocer la ruta gastronómica, y que el turista sea atraído y se interesé por realizarla. Los flyer diseñados se muestran a continuación. 
Año 13.

Revista de Investigación

Núm. 33

Académica sin Frontera

ISSN: 2007-8870

https://revistainvestigacionacademicasinfrontera.unison.mx/index.php/RDIASF

Recibido el 3 de junio de 2020. Dictaminado mediante arbitraje favorablemente 9 de octubre de 2020.

En la figura 4 se muestra uno de los principales flyer de la ruta, en el cual se plasmó una fotografía de la isla al caer el sol, con el objetivo de atraer a el turista por la belleza y la naturaleza que se refleja.

Figura 4. Flyer de la ruta

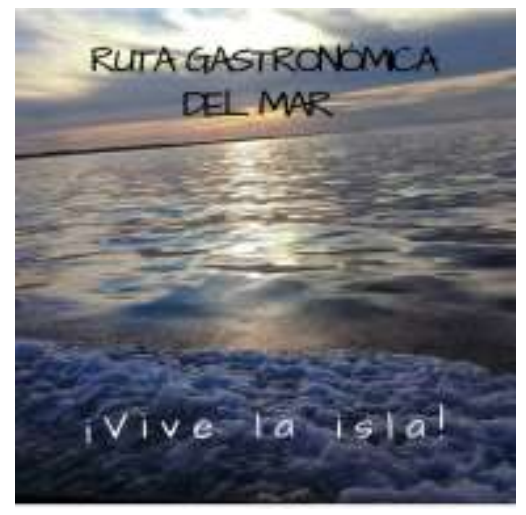

Fuente: (Elaboración propia, 2019).

En la figura 5 se puede observar un flyer de la ruta gastronómica del mar, en él se refleja la gastronomía existente en la localidad con la finalidad de que el turista conozca un poco de lo que se ofrece en el lugar.

Figura 5. Flyer de la ruta 


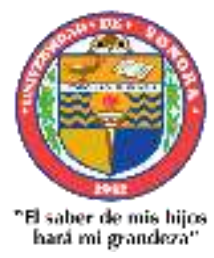

Año 13.

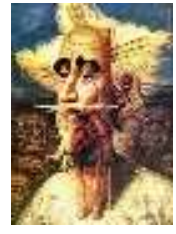

Revista de Investigación Académica sin Frontera

Núm. 33

ISSN: 2007-8870

https://revistainvestigacionacademicasinfrontera.unison.mx/index.php/RDIASF

Recibido el 3 de junio de 2020. Dictaminado mediante arbitraje favorablemente 9 de octubre de 2020.

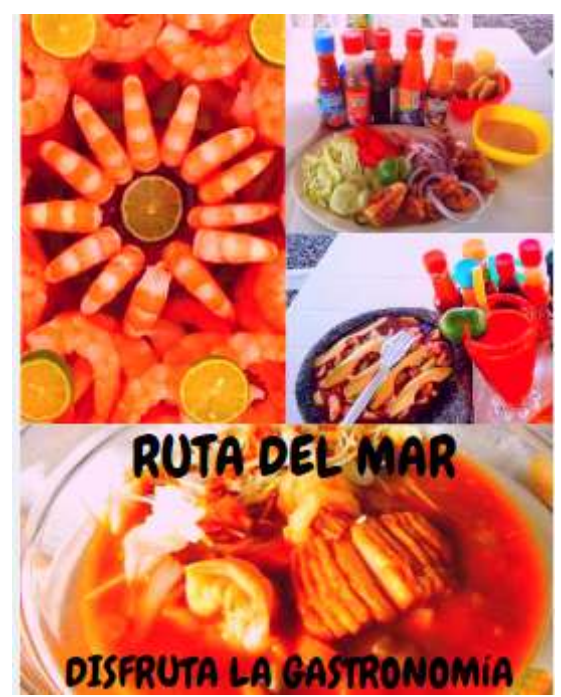

Fuente: (Elaboración propia,2019).

\section{Generación de la idea.}

La ruta consiste en visitar la isla Huivulai y bahía del tobarí, donde principalmente los turistas conocerán y aprenderán sobre el proceso de la captura del marisco, vivirán la experiencia de conocer como es la vida del pescador día a día, también podrán disfrutar de las dunas de arena que esta tiene y visitar las palmas, lugar donde se encuentra la virgen del Carmen, virgen que es venerada por los habitantes de la localidad del Paredón colorado, ya que se le conoce como la virgen de los pescadores.

Después del recorrido a la isla los turistas regresarán a la localidad del Paredón, donde se dirigirán a la casa de la señora Rafaela habitante de la localidad, donde se les brindará la oportunidad de aprender cómo se preparan los principales 


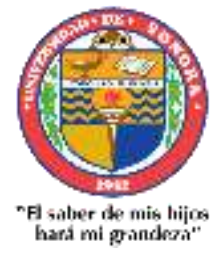

( Julio - Diciembre 2020)

Año 13.

Núm. 33

ISSN: 2007-8870

https://revistainvestigacionacademicasinfrontera.unison.mx/index.php/RDIASF

Recibido el 3 de junio de 2020. Dictaminado mediante arbitraje favorablemente 9 de octubre de 2020.

platillos de la región como son: Lisas ahumadas, Cahuamanta, Machaca de camarón, Coctel de camarón y Tostadas de jaiba.

Después de que los turistas conozcan el proceso de la elaboración de los platillos podrán degustar y convivir con la señora Rafaela, así como hacer preguntas sobre dudas que surgieron o alguna otra receta que les interese conocer.

Para que el turista realice la ruta es necesario que cuente con la vestimenta adecuada, por lo que se sugiere lleve ropa cómoda, zapatos de secado rápido, y gorra, para que puede llevar a cabo las actividades de manera satisfactoria.

Para finalizar con la ruta se brindará un taller de artesanías, que consiste en fabricar aretes, llaveros, espejos, cortineros, pulseras y relojes de pared, se le dará a elegir al turista que artesanía quiere realizar, las artesanías se elaboran con materiales recolectados de la isla como son conchas de mar, caracoles, y caballitos de mar.

La propuesta es que la ruta se ofrezca de jueves a domingo, debido a que los pescadores trabajan entre semana y son quienes ofrecerían el servicio de la lancha para realizar la actividad de visitar la isla.

\section{Análisis de la demanda del mercado.}

El principal mercado al que se dirigirá la ruta es a municipios cercanos a la localidad de Paredón, como lo son Obregón, Navojoa, Villa Juárez y Huatabampo ya que los visitantes en su mayoría son pertenecientes de las ciudades antes mencionadas.

La finalidad de brindarles una ruta gastronómica, es que no solo disfruten de la gastronomía del lugar, sino que vivan la experiencia del proceso que los 


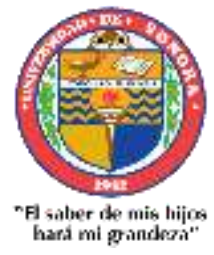

Año 13.

Núm. 33

ISSN: 2007-8870

https://revistainvestigacionacademicasinfrontera.unison.mx/index.php/RDIASF

Recibido el 3 de junio de 2020. Dictaminado mediante arbitraje favorablemente 9 de octubre de 2020.

habitantes del lugar realizan para conseguir el marisco y también integrándolos en la elaboración de artesanías del lugar.

\section{Análisis de la competencia.}

Actualmente la localidad del Paredón colorado no cuenta con un tour operadora que ofrezca una ruta de ningún tipo, sin embargo, hay habitantes que ofrecen paseos en lancha a la isla Huivulai y brindan mariscos a los visitantes, siendo así los habitantes la principal competencia.

\section{Sostenibilidad cultural.}

Al momento de que la ruta se lleve a cabo, se establecerán reglas para minimizar posibles impactos negativos, informando al visitante sobre las consecuencias que tendrá si hace algo indebido en el lugar o si no muestra el respeto adecuado con los señalamientos o reglas establecidas durante la visita, esto con el fin de involucrar a las personas en la conservación de la isla Huivulai.

\section{Diseño de la ruta gastronómica del mar.}

Identificación y caracterización de clientes: como mercado principal al cual va dirigido, será a personas con edad promedio de 18 a 65 años, sea hombre o mujer que tenga interés en visitar la isla y aprender sobre la vida diaria de un habitante de la localidad del Paredón colorado, así como conocer la manera en que se elaboran los platillos típicos del lugar y el proceso que se lleva a cabo para la elaboración de artesanías. Se considera que el producto le es de interés a personas pertenecientes 
Revista de Investigación

Año 13.

Académica sin Frontera

Núm. 33

ISSN: 2007-8870

https://revistainvestigacionacademicasinfrontera.unison.mx/index.php/RDIASF

Recibido el 3 de junio de 2020. Dictaminado mediante arbitraje favorablemente 9 de octubre de 2020.

a los municipios antes mencionados ya que son personas que visitan constantemente la localidad.

Itinerario de la ruta gastronómica.

En la Tabla 2 se puede observar el itinerario que se realizará, mismo que muestra hora y actividades que se llevarán a cabo a lo largo de la ruta gastronómica.

Tabla 2. Itinerario

\begin{tabular}{|l|l|}
\hline Hora & Actividad \\
\hline 7:00 am & Recorrer la isla \\
\hline 7:30 am & Tender el chinchorro y trampas jaiberas \\
\hline 8:15 am & Subir chinchorro y trampas \\
\hline 9:00 am & Visitar las palmas y virgen del Carmen \\
\hline 9:30 am & Caminar por las dunas de arena \\
\hline 9:50 am & Recolectar conchas de mar \\
\hline 10:00 am & Regresar a paredón colorado \\
\hline 10:30 am & Elaboración de platillos típicos \\
\hline 12:30 pm & Degustar los platillos elaborados \\
\hline 1:30 pm & Taller de artesanías \\
\hline 3:30 pm & Terminación de la ruta \\
\hline
\end{tabular}

Fuente: (Elaboración propia, 2019). 
Revista de Investigación

Año 13.

Académica sin Frontera

Núm. 33

ISSN: 2007-8870

https://revistainvestigacionacademicasinfrontera.unison.mx/index.php/RDIASF

Recibido el 3 de junio de 2020. Dictaminado mediante arbitraje favorablemente 9 de octubre de 2020.

\section{Análisis económico de la ruta.}

Evaluación de costos: en la Tabla 3 se muestra la evaluación de costos planeada para que la ruta se llevé a cabo, se pueden observar los conceptos y el monto de inversión que se requiere para la habilitación de cocina y capacitación de habitantes.

Tabla 3. Cotizaciones

\begin{tabular}{|l|l|l|}
\hline \multicolumn{2}{|c|}{ Evaluación de costos } \\
\hline \multirow{4}{*}{ Necesidad de inversión } & Inversión & Monto \\
\cline { 2 - 3 } & Habilitación de cocina & $\$ 1,200$ \\
\cline { 2 - 3 } & Reparación de horno & $\$ 300$ \\
\cline { 2 - 3 } & Capacitación a los habitantes & $\$ 500$ \\
\hline Total & & $\$ 2,000$ \\
\hline \multirow{3}{*}{$\begin{array}{l}\text { Costos operacionales } \\
\text { en base a un grupo de 8 } \\
\text { personas }\end{array}$} & Guía & $\$ 700$ \\
\cline { 2 - 3 } & Alimentación & $\$ 840$ \\
\hline Total & & $\$ 600$ \\
\hline
\end{tabular}

Fuente: (Elaboración propia, 2019).

En la Tabla 4 se muestra la fijación de precios de la ruta, se puede observar el costo total, en grupo de 8 personas y el costo individual, posteriormente se muestra el precio de la ruta por persona. 
Revista de Investigación

Año 13.

Académica sin Frontera

Núm. 33

ISSN: 2007-8870

https://revistainvestigacionacademicasinfrontera.unison.mx/index.php/RDIASF

Recibido el 3 de junio de 2020. Dictaminado mediante arbitraje favorablemente 9 de octubre de 2020.

Tabla 4. Fijación de precios

\begin{tabular}{|l|l|l|}
\hline \multicolumn{3}{|c|}{ Fijación de precios } \\
\hline Se agregará un margen de 40\% & Costo total (8 personas) & $\$ 2,140$ \\
\cline { 2 - 3 } $\begin{array}{l}\text { para la contribución de costos } \\
\text { fijos, gastos comerciales y }\end{array}$ & Costo por persona & $\$ 2,140 / 8=267.5$ \\
margen de utilidad. & Precio venta por persona & $\$$ \\
& & $267.5(40 \%)=107$ \\
& & $\$$ \\
& & $267.5+107=374.5$ \\
\hline
\end{tabular}

Fuente: (Elaboración propia, 2019).

\section{Distribución de la ruta}

Canales de distribución de la ruta: los canales de distribución que se utilizarán para que la ruta se dé a conocer y llegue al visitante será mediante las siguientes maneras:

Flyer, la ruta se dará a conocer mediante flyers que serán colocados en los principales municipios que se quieren atraer.

Redes sociales, constantemente a través de las diferentes redes como son Facebook e Instagram se publicará información sobre la ruta para que llegue a más personas. 


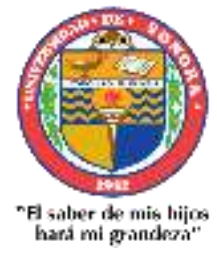

( Julio - Diciembre 2020)

Año 13.

Núm. 33

ISSN: 2007-8870

https://revistainvestigacionacademicasinfrontera.unison.mx/index.php/RDIASF

Recibido el 3 de junio de 2020. Dictaminado mediante arbitraje favorablemente 9 de octubre de 2020.

Página web, se llevará a cabo la creación de una página con el fin de brindar información, videos e imágenes de la isla Huivulai, platillos típicos y elaboración de artesanías.

Difusión por medios electrónicos, esta opción se eligió para dar una atención personalizada, donde se le enviará constantemente información y se resolverán dudas, también es una manera de fidelizar al cliente ya que no todas las empresas de turismo o empresas en general utilizan este medio de comercialización.

\section{Conclusiones}

Al realizar una investigación para el diseño de una ruta gastronómica en la Localidad del Paredón Colorado, se confirma que se cumple el objetivo de la presente investigación anteriormente planteado, ya que diseñar una ruta en dicha Localidad beneficiaria a los habitantes debido a que al implementarla desarrollará su cultura e incrementará la economía del lugar a través de la actividad del turismo.

La propuesta de llevar a cabo una ruta gastronómica dentro de la localidad, generará beneficios sociales y económicos, a través del aprovechamiento de los recursos naturales y culturales con los que se cuenta, así ofreciendo una experiencia al visitante y brindarle un aprendizaje de la cultura que se tiene en Paredón. El implementar la ruta permitirá que los habitantes se interesen por desarrollar el turismo en la localidad y se generen empleos directos e indirectos, así obteniendo otra fuente de ingresos, lo que se pretende es incluir a la localidad en 


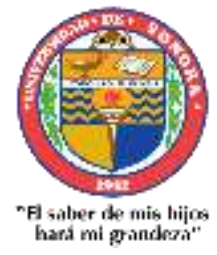

( Julio - Diciembre 2020)

Año 13.

Núm. 33

ISSN: 2007-8870

https://revistainvestigacionacademicasinfrontera.unison.mx/index.php/RDIASF

Recibido el 3 de junio de 2020. Dictaminado mediante arbitraje favorablemente 9 de octubre de 2020.

general con el fin de que mantengan la cultura, tradiciones y costumbres vivas para que futuras generaciones conserven lo antes mencionado.

Para el diseño de la ruta fue necesario evaluar la localidad de Paredón colorado para obtener resultados si se contaba con el potencial necesario para desarrollar e implementar la ruta, dado a que los resultados fueron factibles ya que se cuenta con riqueza natural y cultural, se inició con la creación de la ruta, la cual se espera que a corto plazo se pueda ejecutar, también se buscará que a lo largo del año se puedan ofrecer diferentes rutas, es decir, innovar la ruta o crear nuevas ya que la localidad cuenta con diferentes fiestas tradicionales que se pueden aprovechar para atraer a visitantes para dar a conocer su cultura.

Con la creación de la ruta gastronómica del mar se prevé que será aceptada por parte de los habitantes de la localidad, ya que el principal atractivo del Paredón es la gastronomía del lugar, así como también la elaboración de artesanías. En los restaurantes que se encuentran se puede comprar artesanías que elaboran los habitantes, es por eso que se decidió incluir un taller donde el visitante tenga la oportunidad de aprender a elaborar artesanías.

Por parte de los visitantes se considera que será aceptada porque buscan algo más que comer, es decir realizar actividades y actualmente no se brindan, es por eso que al realizar la ruta se le brindará la oportunidad de vivir la experiencia de cómo viven los habitantes del Paredón y que ellos mismos realicen todo el proceso de la elaboración de los platillos, de igual manera con las artesanías, el realizar la 


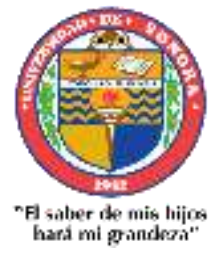

Año 13.

Núm. 33

ISSN: 2007-8870

https://revistainvestigacionacademicasinfrontera.unison.mx/index.php/RDIASF

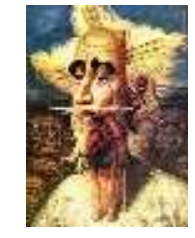

Revista de Investigación

Académica sin Frontera

Recibido el 3 de junio de 2020. Dictaminado mediante arbitraje favorablemente 9 de octubre de 2020.

ruta les dejará una experiencia y un aprendizaje inolvidable, así como también valorarán más la cultura y naturaleza que se tiene en la localidad.

Por último, se recomienda se lleve a cabo un plan de negocios en el cual la localidad en general o habitantes interesados en desarrollar el turismo se organicen para establecer una empresa local, con el fin de que la ruta se opere de una manera formal, así como el de crear nuevas rutas.

También se recomienda brindar capacitaciones de guías, primeros auxilios, calidad en el servicio y manejo de higiene en los alimentos, con el fin de que los habitantes tengan los conocimientos necesarios para saber cómo actuar en cualquier situación que se presente al momento de prestar los servicios.

\section{Bibliografía consultada}

Asesores en Turismo para Empresas e Instituciones Públicas. (2016). APA Style: Electronic references. Recuperado de: https://asesoresenturismoperu.wordpress.com/2016/03/26/definicion-rutaturistica/

Cárdenas E. (2015)., Diseño de una ruta turística gastronómica del Cantón

Riobamba para la valoración y difusión del patrimonio cultural inmaterial. ESCUELA SUPERIOR POLITÉCNICA DE CHIMBORAZO ECUADOR. Recuperado de:

http://dspace.espoch.edu.ec/bitstream/123456789/4227/1/23T0462\%20.pdf 


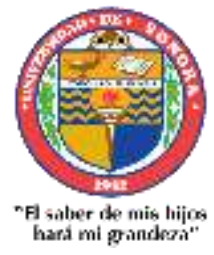

Año 13.

Núm. 33

ISSN: 2007-8870

https://revistainvestigacionacademicasinfrontera.unison.mx/index.php/RDIASF

Recibido el 3 de junio de 2020. Dictaminado mediante arbitraje favorablemente 9 de octubre de 2020.

Casas A., Soler A. y Pastor V. (2012). El turismo comunitario como instrumento de erradicación de la pobreza: potencialidades para su desarrollo en Cuzco Perú. UNIVERSIDAD DE MURCIA. Recuperado de: https://www.redalyc.org/html/398/39824503004/

Centro Empresarial Gastronómico Hotelero. (2015). APA Style: Electronic references. Recuperado de: https://peregrinogastrosofo.wordpress.com/2015/03/16/definicion-rutagastronomica-turistica-y-cultural/

Coriolano L., (2017). Turismo comunitario en el Nordeste Brasileño. UNIVERSIDAD AUSTRAL DE CHILE. Recuperado de: https://www.redalyc.org/pdf/2233/223353239002.pdf

Delgado E. y Gavilánez J. Propuesta de Diseño de una ruta gastronómica en la ciudad de la Urdesa de la ciudad de Guayaquil. ESCUELA SUPERIOR POLITÉCNICA DEL LITORAL. Recuperado de:

https://www.dspace.espol.edu.ec/bitstream/123456789/19175/1/RESUMEN \%20DE\%20TESIS\%20-\%20FINAL.pdf

Enciclopedia de los Municipios y Delegaciones de México. (S.f). Estado de Sonora. APA Style: Electronic References. Recuperado de: http://www.inafed.gob.mx/work/enciclopedia/EMM26sonora/municipios/2607 1a.html

El universal. (2016). Turismo gastronómico Guanajuato. APA Style: Electronic references. Recuperado de: http://archivo.unionguanajuato.mx/articulo/2016/03/09/turismo/guanajuatosi-sabe-tuvo-derrama-de-609-millones 


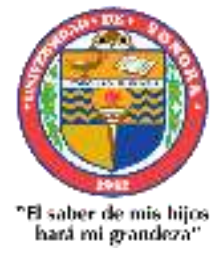

( Julio - Diciembre 2020)

Año 13.

Núm. 33

ISSN: 2007-8870

https://revistainvestigacionacademicasinfrontera.unison.mx/index.php/RDIASF

Recibido el 3 de junio de 2020. Dictaminado mediante arbitraje favorablemente 9 de octubre de 2020.

Fernández G. y Guzmán A., (2005). Patrimonio Industrial y rutas turísticas culturales: algunas propuestas para Argentina. UNIVERDAD DE MURCIA ESPAÑA recuperado de: https://www.redalyc.org/pdf/398/39801506.pdf González M. (2013). Análisis del patrimonio gastronómico entre los Mazahuas de San Antonio Pueblo Nuevo, San José del Rincón, México. UNIVERSIDAD AUTÓNOMA DEL ESTADO DE MÉXICO. Recuperado de:

http://ri.uaemex.mx/bitstream/handle/20.500.11799/13729/412743.pdf?sequ ence $=1$ \&isAllowed $=\mathrm{y}$

Goeldner C. y Brent J., (2011). Introducción al turismo: planeación, administración y perspectivas. México: Limusa Wiley.

Gurría M. (1991). Introducción al turismo. México: Trillas

Hernández R. y Pilar L., (2014). Metodología de la investigación. México

Huertas N., (2015). Turismo rural comunitario como una propuesta metodológica de innovación social para comunidades en conflicto. UNIVERSIDAD DE GIRONA. Recuperado de:

https://www.tdx.cat/bitstream/handle/10803/378657/tnch1de1.pdf?sequence $=6 \&$ isAllowed $=\mathrm{y}$

Lugares turísticos. (2008). APA Style: Electronic references. Recuperado de: https://obson.wordpress.com/2008/12/02/isla-huivulai/

Ministerio de Comercio Exterior y Turismo. (2012). APA Style: Electronic references. Recuperado de: https://www.mincetur.gob.pe/turismo/proyectosen-turismo/

MINCETUR. (2018). Manual para la elaboración y actualización del inventario de recursos turísticos. APA Style: Electronic references. Recuperado de: 


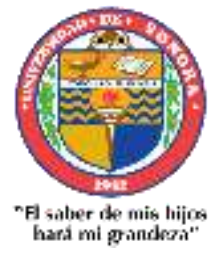

Año 13.

Núm. 33

ISSN: 2007-8870

https://revistainvestigacionacademicasinfrontera.unison.mx/index.php/RDIASF

Recibido el 3 de junio de 2020. Dictaminado mediante arbitraje favorablemente 9 de octubre de 2020.

https://www.mincetur.gob.pe/wp-

content/uploads/documentos/turismo/consultorias/directoriosManuales/Man ual_para_la_Elaboaracion_y_actualizacion_del_inventario_de_recursos_turi sticos.pdf

Montaner J., Antich J. y Arcarons R., (1998). Diccionario de turismo. México: Editorial Síntesis

Organización Mundial de Turismo. S.f. APA Style: Electronic references.

Recuperado de: http://www2.unwto.org/es/content/por-que-el-turismo

Pérez, J. (2017)., Travelreport APA Style: Electronic References. Recuperado de: https://www.travelreport.mx/destinos/playas/huivulai-isla-en-sonora-mexico/

Ruano C., (2012). Diseño de productos y servicios turísticos locales. Málaga: Innova

Salazar, V. (2017). El turismo gastronómico llego para quedarse. APA Style: Electronic references. Recuperado de: http://valentinasalazar.com/turismogastronomico-llego-quedarse/

Rodríguez S., (S.f). El paredón colorado, del mar a su mesa APA Style: Electronic references. Recuperado de:

https://www.elimparcial.com/sonora/ciudadobregon/El-Paredon-Coloradodel-mar-a-su-mesa-20170705-0140.html 


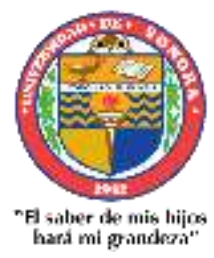

( Julio - Diciembre 2020)

Año 13.

Revista de Investigación

Núm. 33

ISSN: 2007-8870

https://revistainvestigacionacademicasinfrontera.unison.mx/index.php/RDIASF

Recibido el 3 de junio de 2020. Dictaminado mediante arbitraje favorablemente 9 de octubre de 2020.

\section{Directorio Institucional}

Dr. Enrique Fernando Velázquez Contreras

Rector

Dr. Ramón Enrique Robles Zepeda

Secretario General Académico

Dra. Rosa María Montesinos Cisneros

Secretaria General Administrativa

Dr. Rodolfo Basurto Álvarez

Director de Vinculación y Difusión

Dra. Adriana Leticia Navarro Verdugo

Vicerrectora de la Unidad Regional Sur

Dr. Ernesto Clark Valenzuela

Director de la División de Ciencias Económicas y Sociales

Dr. Francisco Espinoza Morales

Secretario de la División de Ciencias Económico y Sociales

Dra. Leticia María González Velásquez

Jefe del Departamento de Ciencias Económico Administrativas

Dra. Lidia Amalia Zallas Esquer

Jefe de Departamento de Ciencias Sociales 


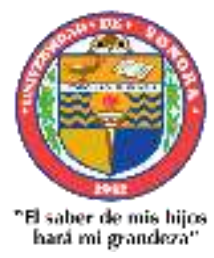

Año 13.

Núm. 33

ISSN: 2007-8870

https://revistainvestigacionacademicasinfrontera.unison.mx/index.php/RDIASF

Recibido el 3 de junio de 2020. Dictaminado mediante arbitraje favorablemente 9 de octubre de 2020.

\section{Comité Directivo}

\section{Editor Responsable}

Dr. Francisco Espinoza Morales

\section{Directora}

Dra. Leticia María González Velásquez

\section{Subdirector}

Dr. Javier Carreón Guillen

\section{Editor Científico}

Dr. Cruz García Lirios

\section{Master Gráfico}

M.T.I. Francisco Alan Espinoza Zallas

Nos complace anunciar que su diario, "Academic Research Journal Withoutborders" (ISSN/EISSN 2007-8870) fue evaluado positivamente en la indexación Citefactor, ahora la página de la revista está disponible en línea, en caso de cualquier problema. Journals Master | International Innovative Journal Impact Factor (IIJIF)

Red Latinoamericana de revistas Académicas en Ciencias Sociales y Humanidades

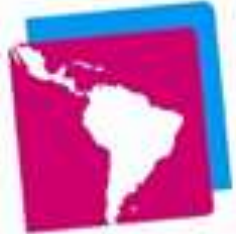

LatinREV

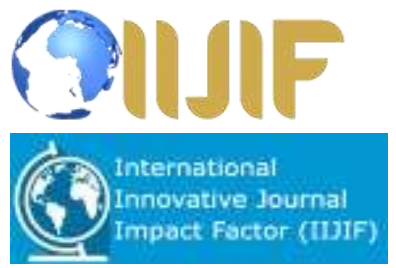




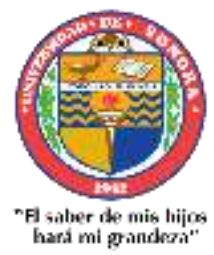

( Julio - Diciembre 2020)

Año 13.

Revista de Investigación

Núm. 33

ISSN: 2007-8870

https://revistainvestigacionacademicasinfrontera.unison.mx/index.php/RDIASF

Recibido el 3 de junio de 2020. Dictaminado mediante arbitraje favorablemente 9 de octubre de 2020.

\section{Comité editorial}

Dra. Angélica María Rascón Larios

Universidad de Sonora. México

Dra. María del Rosario Molina González

Universidad de Sonora

Dra. Francisca Elena Rochin Wong

Universidad de Sonora. México

Dra. Lidia Amalia Zallas Esquer

Universidad de Sonora. México

Dra. Beatriz Llamas Arechiga

Universidad de Sonora. México

Dr. Rogelio Barba Álvarez

Universidad de Guadalajara. México

Dra. Rosa María Rincón Ornelas

Universidad de Sonora. México

Dr. Juan Flores Preciado

Universidad de Colima. México

Dr. Amado Olivares Leal. Universidad de Sonora

Universidad de Sonora. México

Dr. Guillermo Velázquez Valadez.

Instituto Politécnico Nacional (IPN) México

Dr. Hugo Nefstalí Padilla Torres.

Universidad Estatal de Sonora. México

Dr. Luis Ramón Moreno Moreno.

Universidad Autónoma de Baja California. México

Dr. Miguel Ángel Vázquez Ruiz.

Universidad de Sonora. México 


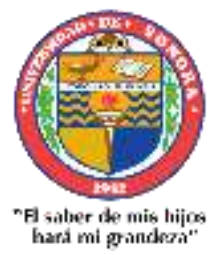

( Julio - Diciembre 2020)

Año 13.

Revista de Investigación

Núm. 33

Académica sin Frontera

ISSN: 2007-8870

https://revistainvestigacionacademicasinfrontera.unison.mx/index.php/RDIASF

Recibido el 3 de junio de 2020. Dictaminado mediante arbitraje favorablemente 9 de octubre de 2020.

Dra. Lorena Vélez García.

Universidad Autónoma de Baja California. México

Dra. Pabla Peralta Miranda.

Universidad Simón Bolívar, Barranquilla, Colombia

Mtro. Roberto Espíritu Olmos

Universidad de Colima (FCA Tecomán) Colima

Dr. Héctor Priego Huertas.

Universidad de Colima (FCA Tecomán) Colima

Mtra. María Guadalupe Alvarado Ibarra.

Universidad de Sonora. México.

MSc. Celso Germán Sánchez Zayas

Universidad de Camagüey, Ignacio Agramonte Loynaz, Cuba

Dra. María Luisa Quintero Soto

Universidad Autónoma del Estado de México

Dr. Eyder Bolivar Mojica

Universidad Católica, Luis Amigó, Medellin, Colombia

Revisores de Textos en Inglés

Mtro. Renato Encinas

Mtra. Cecilia Guadalupe Martínez Solano

\section{Comité científico}

Dr. Rosendo Martínez Jiménez. Universidad Autónoma Benito Juárez de Oaxaca.

Dr. Hugo Neftalí Padilla. Universidad Estatal de Sonora

Dra. María Teresa Gaxiola Sánchez. Universidad de Sonora.

Dr. José Cesar Kaplan. Universidad Estatal de Sonora.

Dr. Alfredo Islas Rodríguez. Universidad de Sonora

Frecuencia de publicación: semestral / 2 números por año. 


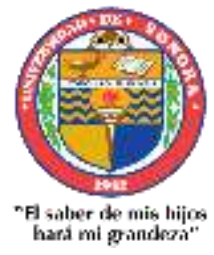

Año 13.

Núm. 33

ISSN: 2007-8870

https://revistainvestigacionacademicasinfrontera.unison.mx/index.php/RDIASF

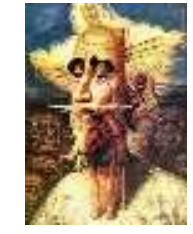

Revista de Investigación

Académica sin Frontera

Recibido el 3 de junio de 2020. Dictaminado mediante arbitraje favorablemente 9 de octubre de 2020.

Revista de Investigación Académica sin Frontera (RIASF) con (ISSN: 2007-8870) es un interlocutor internacional de acceso abierto revisado diario en línea en el ámbito del de las Ciencias Económicas Administrativas y Sociales. Su objetivo principal es dar a los trabajos de investigación de calidad. Cubre todas las sub-campos de los campos anteriormente mencionados. Proporciona la plataforma a académicos, estudiantes y profesionales. Sólo pública trabajos de investigación y artículos de revisión inicial. Documento presentado debe cumplir con algunos criterios como, debe ser original, inédita y no estén sometidos a ninguna otra revista.

RIASF es una revista arbitrada / Revisión por pares International. Publicamos documentos sobre una variedad de temas, contextos y estrategias de análisis que examinan la relación entre la rápida evolución para la Sociedad y la tecnología del conocimiento.

REVISTA DE INVESTIGACIÓN ACADÉMICA SIN FRONTERA, Año 13, No. 33, Julio - diciembre 2020, es una publicación semestral de investigación científica, editada por la Universidad de Sonora, a través de las División de Ciencias Económicas y Sociales, de la Unidad Regional Sur, Blvd. Lázaro Cárdenas No. 100, Col. Francisco Villa, Navojoa, Sonora, Sonora, México, C.P. 85880. Tel. (642) 42599-54.

http://www.revistainvestigacionacademicasinfrontera.com/, revistaacademicasinfrontera@ unison.mx. Editor responsable: Francisco Espinoza Morales. Reserva de Derechos al Uso Exclusivo: 042013-121811323700-203 e ISSN: 2007-8870, ambos otorgados por el Instituto Nacional de Derecho de Autor. Inscrita en el Directorio de LATINDEX, con Núm. De folio 20014, folio único 14590. Responsable de la última actualización de este Número, Unidad Informática de la Universidad de Sonora, fecha de la última modificación, 30 de diciembre 2020, indexada a Cite Factor Academic Scientific Journal y Journals Master (IIJIF) y Red Latinoamericana de Revistas Académicas en Ciencias Sociales y Humanidades, (Latín Rev). Las opiniones expresadas por los autores no necesariamente reflejan la postura del editor de la publicación. Se autoriza la reproducción total o parcial de los contenidos e imágenes en la presente publicación siempre y cuando se cuente con la autorización del editor y se cite plenamente la fuente. 


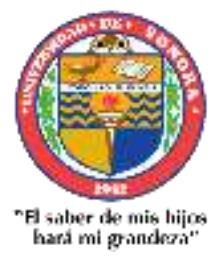

( Julio - Diciembre 2020)

Año 13.

Núm. 33

ISSN: 2007-8870

https://revistainvestigacionacademicasinfrontera.unison.mx/index.php/RDIASF

Recibido el 3 de junio de 2020. Dictaminado mediante arbitraje favorablemente 9 de octubre de 2020.

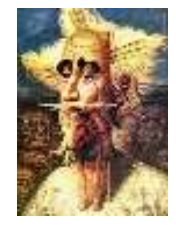

Nos complace anunciar que su diario, "Academic Research Journal Withoutborders" (ISSN/EISSN 2007-8870) fue evaluado positivamente en la indexación Citefactor, ahora la página de la revista está disponible en línea, en caso de cualquier problema.

Journals Master | International Innovative Journal Impact Factor (IIJIF)

Red Latinoamericana de revistas Académicas en Ciencias Sociales y Humanidades
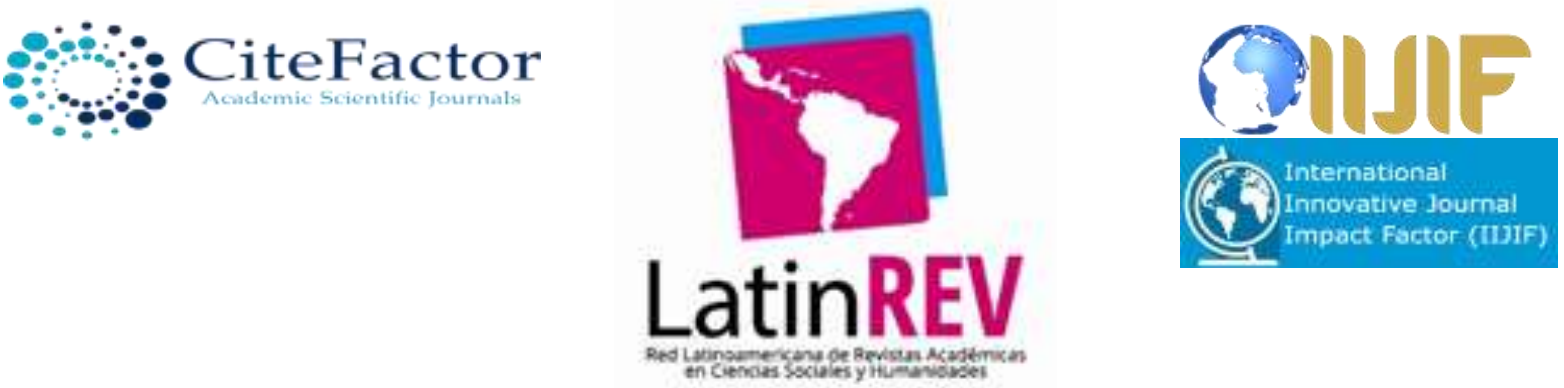

https://www.neliti.com

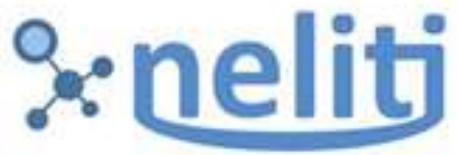

Indonesia's Research Repository
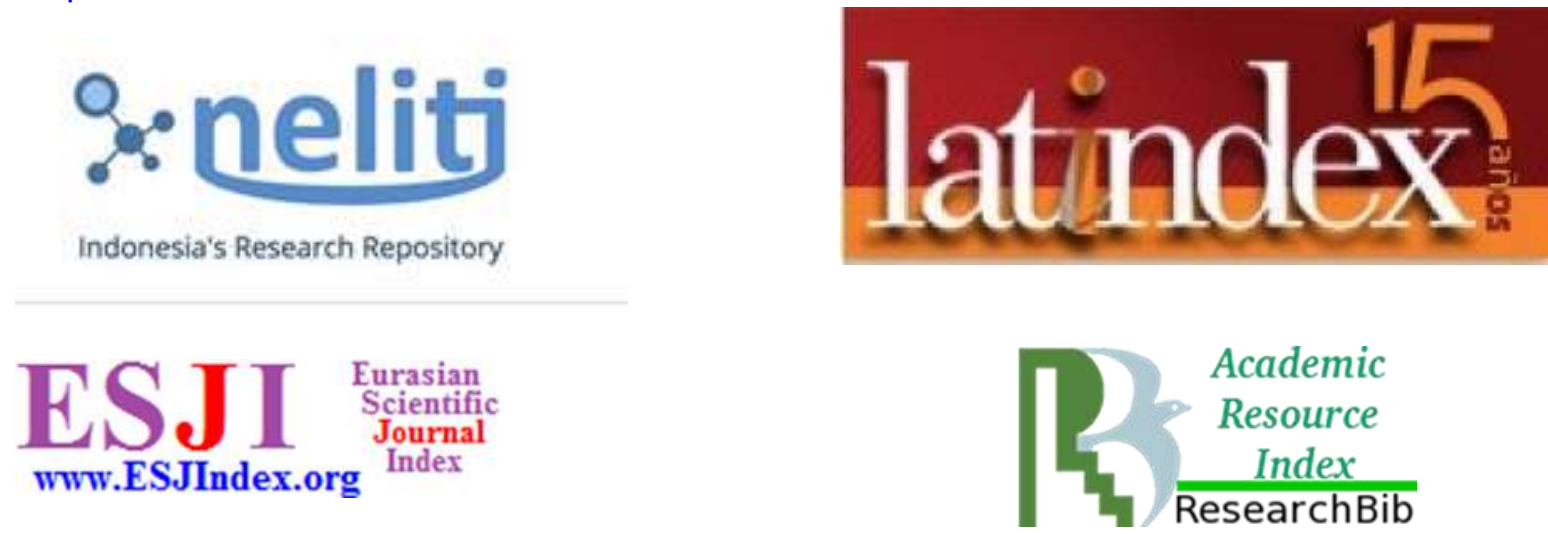